\title{
POR DENTRO DO ESTADO DE SÃO PAULO*
}

\section{Claudio Salvadori Dedecca}

\section{RESUMO}

Este ensaio pretende explorar a informação propiciada pela Pesquisa de Condições de Vida (PCV) com o objetivo de responder à seguinte questão: Em face das tendências de interiorização observadas nas últimas décadas, quais seriam as dimensões mais relevantes no contexto atual que caracterizam ou não a heterogeneidade intra-regional no Estado de São Paulo. O estudo analisa algumas dimensões da configuração socioeconômica do país, com a preocupação de informar as políticas de trabalho e social no Estado.

PALAVRAS-CHAVE: Trabalho; política social; questão regional; renda.

\section{ABSRACT}

The paper explores the microdata of the Pesquisa de Condições de Vida (PCV) with the preoccupation to answer the following question: Given the trends of economic growth of non metropolitan areas observed in recent decades, what are the dimensions most relevant in the actual context for characterize the socioeconomic heterogeneity intra-regional of the State of São Paulo. The study examines some dimensions of socioeconomic transformation in the state with the orientation of to informer the social and labour policies.

KEYWORDS: Labour; social policy; regional policy; income.

[*] Este ensaio é parte do projeto "Regiões metropolitanas e pólos econômicos do Estado de São Paulo: desigualdades e indicadores para as políticas sociais", financiado pela Finep. Agradeço os valiosos comentários e contribuições do parecerista. Com o objetivo de não carregar ainda mais o ensaio com tabelas e gráficos, alguns deles foram suprimidos. As tabulações adicionais estão à disposição do leitor quando solicitados via e-mail.
Desde a segunda metade dos anos de 1970, observase um movimento de interiorização da população e da atividade econômica no Estado de São Pauloํ. Nessa década, o Estado convivia com uma única grande conglomeração urbana, a Região Metropolitana de São Paulo (RMSP). Atualmente duas outras regiões estão consolidadas - Baixada Santista e Campinas - sendo que em Sorocaba e São José dos Campos o processo se encontra em estado avançado. Além disso, outros pólos econômicos regionais vêm sendo constituídos ao longo dos últimos trinta anos. 
Há consenso sobre uma ampla transformação das estruturas de população e de atividade econômica no território paulista, exigindo do gestor público uma crescente atenção sobre processos em curso para além daqueles observados na Região Metropolitana de São Paulo². Mesmo porque a formação de outras regiões metropolitanas ao redor daquela que ainda concentra metade da população e da produção do Estado amplia a integração entre elas, acabando por exigir uma visão sistêmica das relações existentes e potenciais que elas estabelecem ou possam estabelecer entre si.

Até pouco tempo, as evidências sobre este processo, oriundas muitas vezes das demandas por políticas públicas sociais e de infraestrutura, encontravam razoável dificuldade de avaliação em razão da ausência de informação atualizada, especialmente sobre as transformações socioeconômicas ocorridas no Estado. A informação existente encontrava-se restrita à Região Metropolitana, mesmo porque os maiores problemas econômicos e sociais urbanos do Estado ali se concentravam, bem como tendiam a apresentar maior potencial de amplificação de suas conseqüências para o desenvolvimento paulista.

Contudo, a recorrência do processo de interiorização destas últimas décadas foi exigindo maior atenção para as transformações sociais eeconômicas em curso para além da Região Metropolitana, induzindo mudanças na configuração institucional do próprio Governo do Estado, que foi obrigado a ampliar funções que, até então, estavam concentradas na sua grande metrópole. A mudança significou a necessidade de ter mais informações sobre o interior do Estado, levando as instituições públicas a iniciar um processo de pesquisa que permitisse ampliar o conhecimento sobre a diversidade regional por dentro do Estado de São Paulo.

A Fundação Seade teve um papel determinante nessa iniciativa, formulando levantamentos estatísticos por estabelecimento e domicílios e disponibilizando informações mais atualizadas sobre a configuração socioeconômica paulista, o que permitiu um conhecimento mais profundo do que ocorria no tecido produtivo e social do Estado.. Recentemente, esta fundação divulgou os resultados da Pesquisa de Condições de Vida - PCV realizada em 2006, liberando também os dados sobre produção (valor agregado) dos municípios paulistas em nova base metodológica.

Isso abriu a possibilidade de análise da transformação socioeconômica no Estado a partir de informações mais recentes, o que até então estava circunscrito aos resultados do Censo Demográfico 2000. A Pesquisa sobre Condições de Vida permitiu, pois, analisar a configuração socioeconômica do Estado no contexto atual, bem como conhecer o acesso da população aos novos programas sociais, como o Programa Saúde da Família, e às diversas modalidades dos projetos de transferência de renda.
[1] Sobre o processo de interiorização, ver Machado Bógus, L e Baeninger. R.Redesenhando o espaço no interior paulista: desconcentração e expansão urbana. São Paulo: Fundação Seade, 1995; Oliveira, A. “Conhecendo o interior paulista, o papel do espaço na dinâmica do mercado de trabalho". São Paulo em Perspectiva, vol. 20, $\mathrm{n}^{\circ} 4$, 2006.

[2] Ver a esse respeito Cano, W. e outros. Economia paulista: dinâmica sócio-econômica entre 1980 e 2005. São Paulo: Alínea, 2007. 
[3] "Pesquisa de condições devida". Documentação da Base de Dados. São Paulo: Fundação Seade, 2007.
Este ensaio pretende explorar a informação propiciada pela PCV com o objetivo de responder à seguinte questão: Diante das tendências de interiorização observadas nas últimas décadas, quais seriam hoje as dimensões mais relevantes que caracterizam ou não a heterogeneidade intra-regional no Estado de São Paulo?

Inicialmente, uma breve apresentação metodológica da PCV evidenciará o potencial e os limites metodológicos do levantamento. Em seguida, serão analisadas algumas informações socioeconômicas do país, com a preocupação de situar o Estado de São Paulo nas transformações econômicas e sociais recentes. Por fim, serão exploradas as informações da PCV com foco na configuração regional presente no Estado, no que diz respeito à dimensão da sua heterogeneidade econômica e social.

\section{A PESQUISA de CONDIÇões de VIDA - PCV}

A Pesquisa de Condições de Vida foi realizada, pela primeira vez, em 1990 e depois nos anos de 1994, 1998 e 2006. De acordo com a documentação disponível para o último levantamento, a Fundação Seade informa que, "com a finalidade de prover a Casa Civil do governo do Estado de São Paulo e o Projeto Cobertura e Efetividade dos Programas Focalizados no Estado de São Paulo de informações qualificadas sobre a cobertura e formas de acesso a programas focalizados, sobre seu público-alvo e a população atendida, com ênfase na avaliação das ações sociais implementadas, foi realizada, em 2006, a Pesquisa de Condições de Vida - PCV por meio de um levantamento domiciliar por amostragem no Estado de São Paulo em 20 mil domicílios"3.Ainda segundo este documento,

[... ] e escopo temático bastante extenso contemplou: caracterização dos domicílios e suas condições habitacionais, características da família e seu patrimônio, acesso a programas de transferência de renda e outros programas governamentais, características demográficas dos indivíduos, acesso e utilização de serviços de saúde, situação educacional, identificação dos portadores de deficiência física e mental, participação associativa, acesso a Internet, inserção no mercado de trabalho, benefícios do trabalho e rendimentos. Olevantamento, dada a sua amplitude, permite que analistas e formuladores de políticas públicas verifiquem a situação socioeconômica da população paulista, além de observar as desigualdades entre as várias regiões do Estado.

Apesar de o levantamento não permitir uma análise dos resultados no âmbito municipal, ele possibilita uma desagregação respeitável da informação com a seguinte configuração: Região Metropolitana de São Paulo, Região Metropolitana da Baixada Santista, Região Administra- 
tiva de Campinas, Região Administrativa de Sorocaba, Região Administrativa de São José dos Campos, Região Administrativa de Registro, Aglomerado Central Norte (composto pelas regiões administrativas Central de Bauru, Ribeirão Preto e Franca) e Aglomerado Noroeste (composto pelas regiões administrativas de Barretos, São José do Rio Preto, Araçatuba, Marília e Presidente Prudente) (ver Figura 1).

FIGURA I

Mapa do Estado de São Paulo segundo Regiões da Pesquisa de Condições de Vida

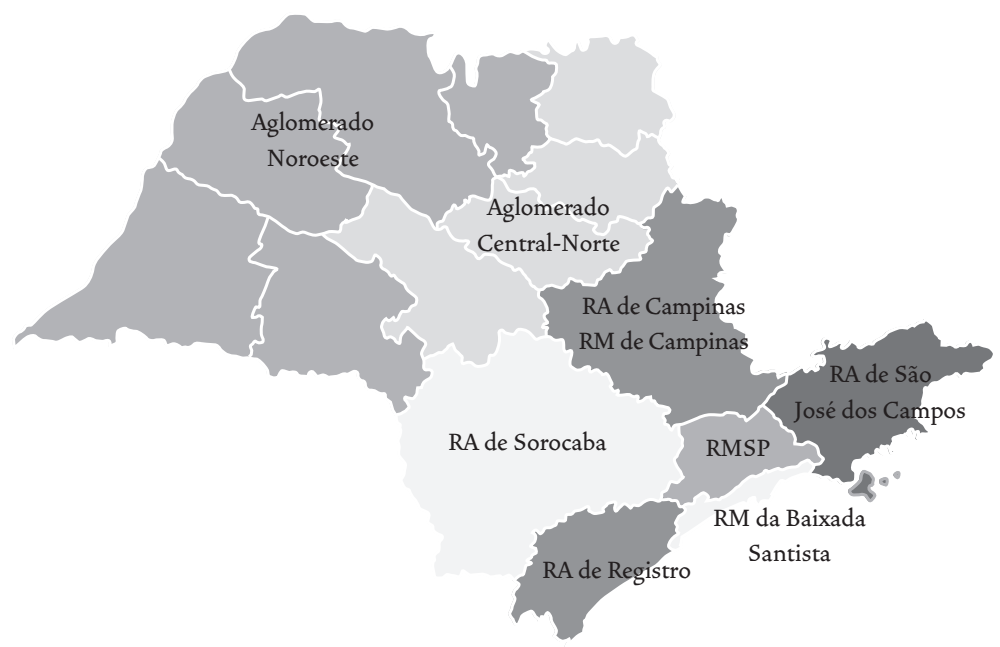

Fonte: Fundação Seade.

O desenho amostral adotado permite uma clara identificação das regiões metropolitanas atuais e daquelas em processo de formação, bem como da Região Administrativa de Registro, em razão de seu isolamento em relação às demais regiões administrativas agrupadas nos conglomerados Centro-Norte e Noroeste.

Segundo estimativa da Fundação Seade, as regiões metropolitanas atuais e aquelas em formação respondiam, em 2005, por aproximadamente $77 \%$ da população do Estado de São Paulo (Tabela 1). Apesar do processo de interiorização observado nas últimas décadas, as três regiões concentravam um pouco mais de $3 / 4$ da população paulista, isto é, três de cada quatro paulistas continuam a residir nas regiões que foram base do processo de industrialização do Estado entre 1930 e 1980 .

A pesquisa possibilita a construção de um quadro analítico abrangente da atual configuração socioeconômica do Estado de São Paulo. Os principais temas abordados são: condições habitacionais, inserção no mercado de trabalho, migração, renda, acesso a serviços de saúde, situação educacional e acesso a programas sociais de transferência de renda. 


\begin{tabular}{|c|c|c|c|}
\hline & \multicolumn{2}{|c|}{ População total } & \multirow[b]{2}{*}{$\begin{array}{c}\text { Taxa anual } \\
\text { de crescimento }\end{array}$} \\
\hline & 2002 & 2005 & \\
\hline Total & $38.123,695$ & $39.949,487$ & 1,57 \\
\hline Região Metropolitana de São Paulo & $17.993,303$ & $18.734,654$ & 1,35 \\
\hline RM da Baixada Santista & $1.531,461$ & $1.625,115$ & 2,00 \\
\hline RA de Campinas & $5 \cdot 324,678$ & $5.634,382$ & 1,90 \\
\hline RA de Sorocaba & $2.561,788$ & $2.723,927$ & 2,07 \\
\hline RA de São José dos Campos & $2.057,439$ & $2.179,192$ & 1,93 \\
\hline RA de Registro & 270,257 & 281,724 & 1,39 \\
\hline Aglomerado Central Norte & $3.604,679$ & $3 \cdot 778,251$ & 1,58 \\
\hline Aglomerado Noroeste & $4.780,090$ & $4.992,242$ & 1,46 \\
\hline
\end{tabular}

Fonte: Fundação Seade.

[4] Deve-seconsiderar com cuidado a redução da desigualdade de renda, pois ela ocorre entre a população com renda proveniente do trabalho ou da proteção social. Nada se sabe muito a respeitoda distribuição derenda entre as diversas formas de rendimento do trabalho, da proteção social e da propriedade de ativos de capital. Sobre os limites da análise da distribuição de renda, ver Dedecca, C. “A redução da desigualdade no Brasil, uma estratégia complexa". In: Paes de Barros, R., Foguel, M. e Ulyssea, G. Desigualdade de renda no Brasil: uma análise da queda recente. Brasília: Ipea, 2007, vol. 1, e Salm, C. "Sobre a recente queda da desigualdade de renda no Brasil: uma leitura crítica”. In: Paes de Barros, R., Foguel, M.e Ulyssea, G., op. cit.
Não seria possível no âmbito deste artigo explorar todo o potencial $\mathrm{da} \mathrm{PCV}$, o que requereria o envolvimento de pesquisadores com o propósito de realizar uma análise de natureza transversal.Aqui serão considerados alguns aspectos ou questões considerados mais relevantes para uma primeira abordagem sobre as dimensões da heterogeneidade socioeconômica predominante no Estado.

\section{EVOLUÇÃO E ESTRUTURA DO PRODUTO INTERNO BRUTO DO ESTADO DE SÃO PAULO}

A recuperação da economia entre 2003 e 2008 tem produzido impactos limitados, mas positivos do ponto de vista social. O incremento da atividade econômica tem sido acompanhado por uma recuperação ponderável do mercado de trabalho, em especial de seu segmento formal. Além disso, as políticas públicas de salário mínimo e de transferência de renda têm permitido uma recuperação relativamente mais acentuada dos baixos rendimentos, determinando uma redução da desigualdade de renda 4 .

Os efeitos positivos da recuperação econômica e das políticas sociais para a reconstituição do nível de emprego e para a elevação da renda real da população mais pobre possibilitaram somente a redução da tensão social decorrente dos efeitos perversos do longo período de ausência de crescimento.Apesar de uma queda respeitável, o desemprego mantinha ainda no final de 2008 um elevado nível e estava associado a um grau de informalidade significativo. A recuperação econômica parece não ter sido capaz de alterar o quadro social de ponderável precariedade de ocupação e renda, bem como de acesso aos bens públicos. 
A modificação dessa configuração social depende tanto da continuidade da expansão econômica, que deverá ser atenuada ou contida em 2009 e 2010, como do curso das políticas públicas existentes de natureza econômica ou social. A conjunção entre crescimento e políticas públicas tem maior expressão no Estado de São Paulo seja em razão do grau de complexidade de sua estrutura produtiva, seja devido à capacidade financeira e gerencial potencial do Estado em adotar políticas públicas orientadas para o desenvolvimento econômico e social paulista.

O crescimento econômico não é condição suficiente para modificar a atual configuração social no Estado, porém é inegável a importância de seus efeitos potenciais e positivos sobre o mercado de trabalho e a capacidade de financiamento das políticas públicas.Analisando o comportamento recente do produto interno bruto do Estado de São Paulo, entre 2002 e 2005 , nota-se um desempenho médio de $3 \%$ ao ano (a.a.) para um crescimento da população de 1,5\%, aproximadamente. Considerando o crescimento populacional mais baixo do Estado, evidenciase prontamente que mesmo um crescimento limitado, da ordem de $3 \%$ a.a., tem a capacidade de provocar o aumento da renda per capita.

O comportamento do PIB estadual ao longo da década foi marcado pelo desempenho positivo da maioria dos setores, com exceção da agropecuária5. Em razão da crescente integração entre a atividade agrícola e a industrial, caracterizada pelos complexos agroindustriais, é provável que parte do desempenho agrícola tenha sido apropriada pela atividade industrial, explicando o comportamento desfavorável do setor como um todo.

Se, em termos gerais, o Estado de São Paulo tem se aproveitado da recuperação econômica entre 2004 e 2008 , podendo ou devendo mesmo seconstituirem centro propulsor desse movimento, observa-se uma evolução bastante diferenciada do produto quando consideradas as regiões definidas pela PCV.O desempenho mais expressivo ocorreu nas regiões de São Paulo, Sorocaba e Campinas, espaço que vem progressivamente configurando uma provável macrorregião. Em seguida, aparece a Baixada Santista, com concentração na atividade portuária e no complexo petroquímico e siderúrgico de Cubatão, e do Aglomerado Central-Norte, com ampla presença dos complexos sucroalcooleiro e de suco de laranja ${ }^{6}$.

Outras três regiões aparecem em situação mais desfavorável.A Região de Registro, apesar de ter apresentado um resultado positivo, ficou muito abaixo de outras que tiveram desempenho reduzido em seu PIB. Sendo a região menos desenvolvida do Estado, com uma economia centrada na pequena agricultura de baixa produtividade, ela apresenta maiores dificuldades para alcançar um desempenho econômico mais expressivo. Restrições ambientais decorrentes da topografia e das áreas de preservação impedem uma transformação significativa da base produtiva local.
[5] Para o período entre $2002 \mathrm{e}$ 2005, a evolução do valor adicionado setorial foi a seguinte:-o,1\% a.a.para a agropecuária, $3.2 \%$ para a indústria de transformação, 3,0\% para os serviços privados e 2,8\% para a administração pública.

[6] Sobre a configuração econômica e da rede urbana do Estado de São Paulo,verIpea/IBGE/Nesur/IE/Unicamp. Caracterização e tendências da rede urbana no Brasil. Campinas: IE/ Unicamp, 1999, pp. 182-242. Sobre a configuração da atividade agrícola, ver Belik, W., Bolliger. F. e Graziano da Silva, J. "Agroindústria paulista: heterogeneidade e reestruturação". São Paulo em Perspectiva, vol. 13, $\mathrm{n}^{\circ}$ 1-2, 1999. Para uma abordagem setorial da trajetória econômica recente do Estado, ver Cano, W. e outros, op.cit. 
Taxas Anuais de Crescimento do Produto Interno Bruto e segundo Regiões Estado de São Paulo, 2002-2005

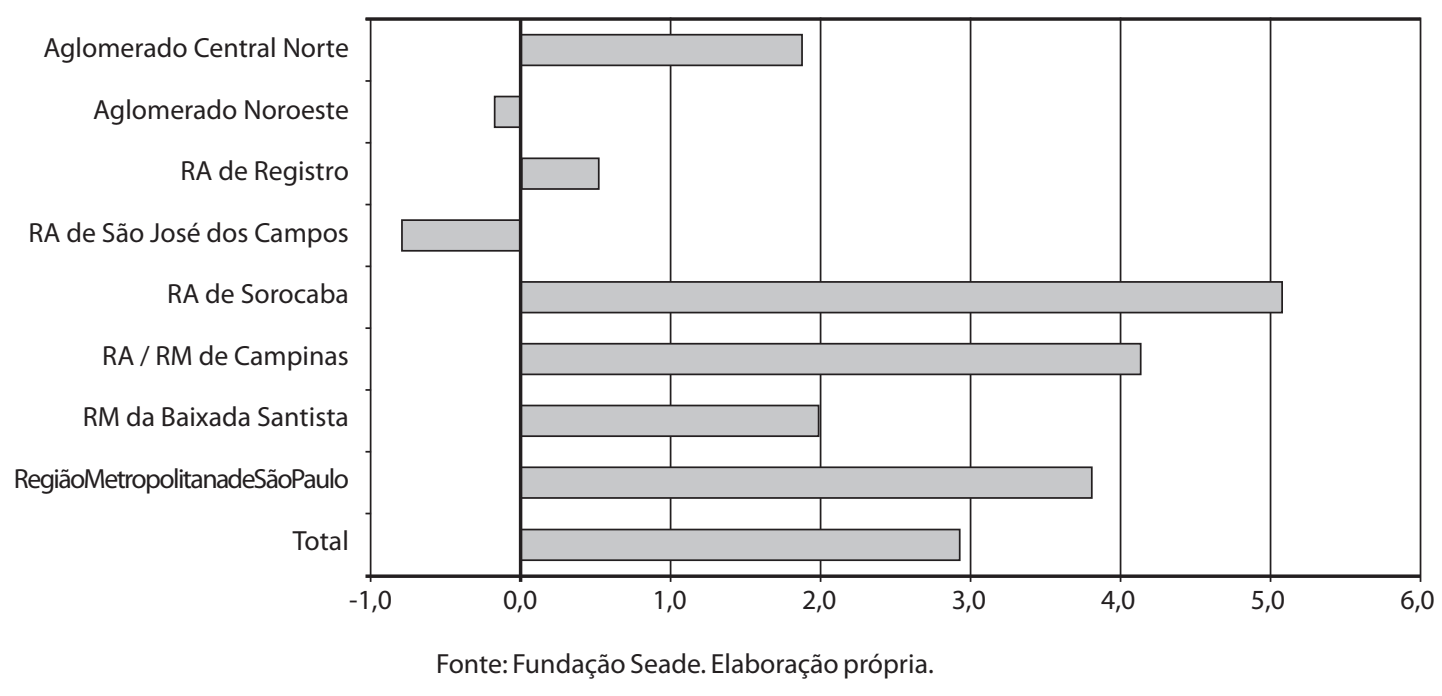

[7] A grande exceção na base industrial de São José dos CamposéaEmbraer.Tantoocomplexo automotivo, como o eletrônico ou de bens intermediários voltam-se, preferencialmente, para o mercado interno.
No que diz respeito ao Aglomerado Nordeste, a região continua tendo uma importante referência de sua economia na atividade agrícola, ainda com uma razoável produção agropecuária e de alimentos para o mercado interno. O perfil da atividade produtiva da região vem se transformando progressivamente, com a expansão da fronteira da cana-de-açúcar. O processo encontrase em franca consolidação, devendo levar a mudanças importantes na estrutura produtiva, bem como na estrutura social prevalecente na região.

ARegiãodeSãoJosédosCamposécaracterizada porumgrande contraste entre a existência de um pólo industrial dominado por grandes empresas nacionais e internacionais e uma agricultura de menor produtividade e em grande medida voltada para o consumo local. O desempenho econômico desfavorável da região deve estar relacionado com o baixo impacto da recuperação econômica, induzida pelo mercado externo, tanto para as atividades industriais 7 , mais voltadas para o mercado interno, como para as atividades agrícolas, não associadas à exportação.

Os dados de valor adicionados mostram que a Região Metropolitana de São Paulo e aquelas situadas em seu entorno respondiam, em 2005, por cerca de $80 \%$ do Produto Interno Bruto do Estado. Apesar da tendência de descentralização da atividade econômica no território estadual, nota-se ainda uma elevada concentração do PIB nas regiões que tradicionalmente centralizaram o desenvolvimento do Estado ao longo do século XX, especialmente na metrópole paulistana, que continua a responder por mais de $50 \%$ a atividade do Estado. 
Apesar das discrepâncias de estruturas produtivas e de desempenho observadas, não se pode afirmar que haja desequilíbrio entre as distribuições do produto e de população entre regiões do Estado (ver Gráfico 2). Participações próximas de produto e população são encontradas para as demais regiões. A avaliação das tendências e da composição do PIB paulista indica que o crescimento recente foi distribuído por todo território do Estado segundo a estrutura populacional prevalecente, sinalizando uma razoável integração de seu tecido produtivo.

Do ponto de vista econômico, duas regiões demandam maior atenção da política pública em razão do processo de transformação em curso, no caso do aglomerado Nordeste, ou de particularidades produtivas, como observado para a Região de Registro.

\section{A DINÂMICA DEMOGRÁFICA RECENTE}

Segundo a Fundação Seade, a população do Estado de São Paulo, em 2007 , era próxima a 40 milhões de pessoas, sendo que $47 \%$ residiam na Região Metropolitana. Mesmo considerando o processo de desconcentração econômica e populacional, já mencionado anteriormente, é inegável que a principal região metropolitana paulista deve requerer boa parte dos resultados do desempenho econômico do Estado por conta de sua dimensão populacional. O mesmo argumento vale para a distribuição das ações das políticas públicas sociais. A redução das necessidades de recursos produtivos e de política sociais pela Região Metropolitana somente poderá ocorrer no longo prazo.

\section{GRÁFICO 2}

Composição do Valor Adicionado e da População segundo Regiões

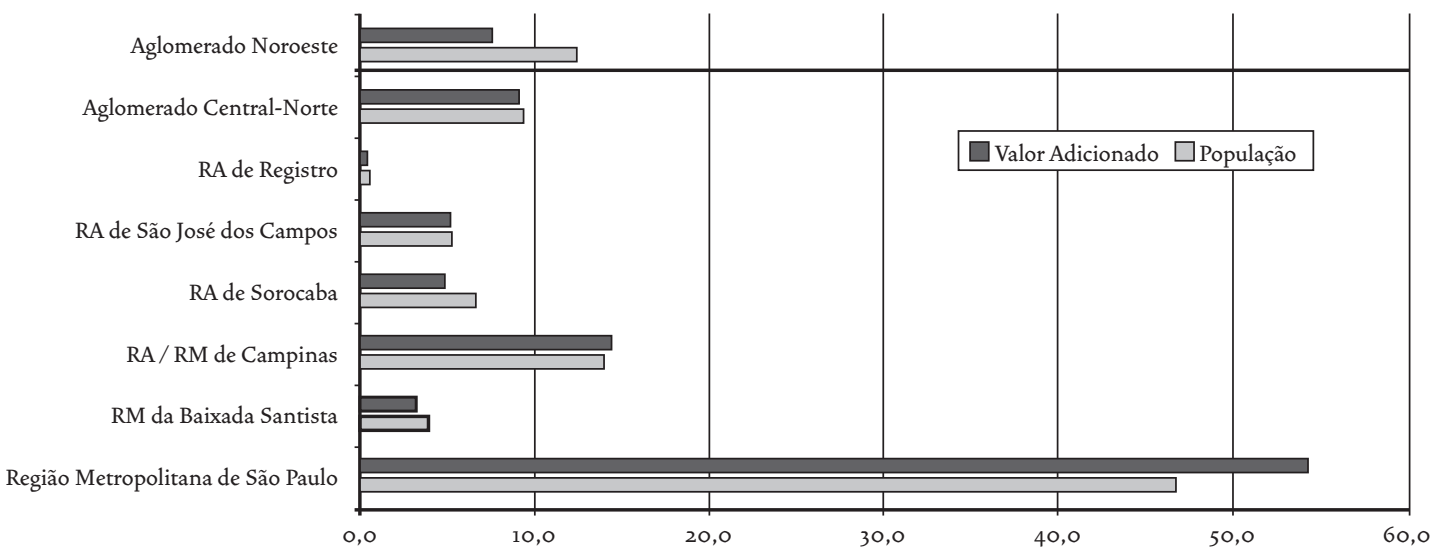

Fonte: Fundação Seade. Elaboração própria. 
[8] Sobre o tema da interiorização e os processos migratórios, ver Baeninger, R. “Interiorização da migração em São Paulo: novas territorialidades e novos desafios teóricos". Anais do XIV Encontro Nacional de Estudos Populacionais, Caxambu:Abep, 2004.
Em suma,é preciso reconhecer que, ao menos considerando a tendência atual, a Região Metropolitana de São Paulo perderá participação na distribuição populacional do Estado nas próximas décadas. Se, no curto prazo, ela continua a demandar parcela dominante dos resultados do crescimento e dos recursos públicos disponíveis, percebe-se que, em prazo mais longo, tal demanda será decrescente devido ao fato de seu crescimento populacional apresentar a mais baixa taxa entre as diversas regiões consideradas pela PCV. É preciso ressaltar, entretanto, um padrão demográfico de baixo crescimento para o Estado como um todo. Nas regiões com taxas mais elevadas - Baixada Santista e Sorocaba - , o incremento populacional encontra-se próximo de $2 \%$ a.a, patamar pouco superior àquele considerado como de reprodução da população residente.

As baixas taxas de crescimento populacional nas diversas regiões do Estado sinalizam que o processo migratório parece ter deixado de ter influência relevante para a dinâmica demográfica paulista. Se do ponto de vista da estrutura populacional atual a parcela total de população migrante apresenta uma dimensão respeitável, nota-se que a migração recente não apresenta uma participação substantiva. Segundo os resultados da PCV, $46 \%$ da população residente declarou ser migrante, tanto as pessoas que nasceram ou moraram em outros Estados como aquelas que declararam tal situação em relação a municípios do próprio Estado de São Paulo.

Analisando a parcela de migrantes com residência de até três anos no Estado, percebe-se que ela representava, em $2006,4,7 \% \mathrm{da}$ população total. É importante observar que, como apontam outros estudos, essa participação não se traduz em um movimento cumulativo, devido à importância do retorno para a população com mais tempo de migração ${ }^{8}$.

O aspecto mais relevante a ser apontado é o fato de a migração recente não ser predominantemente de baixa renda, o que contradiz a visão comum e preconceituosa do processo migratório associado a trabalhadores de baixa qualificação (Tabela 2). A exceção é a Região Central Norte, onde migrantes recentes responderam por $12,7 \%$ dos membros do primeiro decil (extrato) de renda familiar. Considerando-se a Região Metropolitana, nota-se que a participação da migração recente não se diferencia substancialmente entre o $1^{\circ}$ e $010^{\circ}$ decil de renda familiar percapita.

Os resultados evidenciam uma menor importância da migração para a dinâmica populacional do Estado, e indicam que este movimento hoje é bem mais complexo do que no passado, quando a migração se concentrava em populações de baixa remuneração e qualificação. 


\begin{tabular}{|c|c|c|c|c|c|c|c|c|c|c|c|}
\hline & $1^{\circ}$ Decil & $2^{\circ}$ Decil & $3^{0}$ Decil & $4^{0}$ Decil & $5^{\circ}$ Decil & 6 $6^{\circ}$ Decil & $7^{0}$ Decil & $8^{\circ}$ Decil & $9^{\circ}$ Decil & $10^{\circ}$ Decil & Total \\
\hline Total & 5,7 & 5,0 & 6,7 & 6,2 & 6,3 & 3,1 & 3,3 & 3,9 & 2,9 & 4,5 & 4,7 \\
\hline RM de São Paulo & 5,2 & 5,0 & 7,2 & 6,7 & 7,9 & 2,7 & 4,0 & 4,5 & 3,7 & 4,1 & 5,0 \\
\hline Baixada Santista & 2,4 & 6,2 & 4,4 & 4,7 & 2,2 & 5,2 & 2,7 & 13,1 & 4,9 & 3,7 & 4,9 \\
\hline RA de Campinas & 6,6 & 6,3 & 6,1 & 8,1 & 3,3 & 2,6 & 1,9 & 3,0 & 1,7 & 5,8 & 4,6 \\
\hline RA de Registro & 2,6 & 4,6 & 6,0 & 2,2 & 6,0 & 2,3 & 1,0 & 6,4 & 3,6 & 4,3 & 4,0 \\
\hline RA de Sorocaba & 2,1 & 1,1 & 5,5 & 5,7 & 4,3 & 6,5 & 0,7 & 0,2 & 0,5 & 6,0 & 3,8 \\
\hline RA de São José dos Campos & 4,8 & 2,9 & 5,2 & 1,6 & 5,2 & 4,9 & 0,9 & 3,1 & 0,3 & 6,2 & 4,1 \\
\hline Aglomerado Central Norte & 12,7 & 6,4 & 7,9 & 5,6 & 9,0 & 3,1 & 6,6 & 3,7 & 2,5 & 3,9 & 5,7 \\
\hline Aglomerado Noroeste & 6,4 & 4,3 & 6,3 & 4,4 & 3,7 & 1,4 & 2,1 & 0,0 & 2,3 & 3,2 & 3,4 \\
\hline
\end{tabular}

(1) As rendas para as definição dos decis correpondem aos resultados obtidos para o total do Estado de São Paulo. Fonte: Pesquisa de Condições de Vida - PCV/Seade. Microdados. Elaboração própria.

Ainda explorando os dados sobre a dinâmica demográfica recente, o baixo crescimento indica a consolidação de um progressivo envelhecimento da estrutura populacional do Estado de São Paulo9, com implicações tanto para a evolução do mercado de trabalho, como para a demanda de políticas sociais mais orientadas para a população adulta e de idade mais avançada.

\section{A DIVERSIDADE SOCIOECONÔMICA A PARTIR DA ÓtICA DA RENDA FAMILIAR}

A análise aqui empreendida tem a renda familiar como referência básica para a elaboração de indicadores socioeconômicos ou de acesso a políticas públicas, uma vez que ela expressa a estratificação social existente.

Os estratos de renda (decis) foram calculados para o total das famílias do Estado de São Paulo, e não para cada uma das regiões adotadas pela PCV. Por exemplo, a maior ou a menor concentração de população nos decis inferiores em determinada região, em comparação com o que foi observado para o conjunto do Estado, indica que ela apresenta perfil relativamente mais desfavorável. Esse procedimento permite revelar a situação socioeconômica de cada região em relação à média do Estado.

Todos os indicadores de mercado de trabalho ou de acesso aos bens ou às políticas públicas foram elaborados considerando os decis de renda familiar. A adoção desta referência básica para tabulação de resultados impôs que se considerasse somente a parcela da população com rendimento familiar diferente de zero. 
Segundo a PCV, $84 \%$ das famílias declararam ter renda diferente de zero em 2006. Observou-se que a maior porcentagem de famílias com declaração de renda estava no Aglomerado Central Norte (89\%) e a menor na Região deSãoJosédos Campos $(75 \%)$.Estes resultados mostram que ao menos $3 / 4$ das famílias declararam renda diferente de zero, parcela suficiente para dar representatividade aos indicadores elaborados e analisados ao longo deste ensaio. Tal critério equivale a uma estimativa de 10,4 milhões de famílias para o conjunto do Estado, segundo a PCV.

Consideradas as distribuições em cada uma das regiões, constatase que a Região Metropolitana é a que apresenta a maior parcela de famílias com renda mais elevada, ao passo que a Região de Registro apresenta a parcela mais significativa de famílias com baixa renda. Contudo, não se pode dizer que haja diferenças relevantes entre as distribuições no sentido de apontar perfis substantivamente diferentes de distribuição das famílias. De acordo com os resultados apresentados na Tabela 4, metade das famílias paulistas possuía uma renda total de até $R \$ 1.000,00$. É inegável o baixo padrão de renda dominante no Estado como um todo, independentemente da região.

Dando seguimento ao estudo, para avaliaro acesso às políticas sociais por parte da população paulista é importante que se analise também o potencial das famílias para o mercado de trabalho e a inserção de seus membros..

Os dados da PCV (Tabela 3) mostram que as taxas médias de participação econômica das diversas regiões estão entre $50 \%$ e 60\%. Nos extremos temos as regiões de Registro (47\%) e de São Paulo (62\%).O indicador médio reflete o patamar encontrado nos estratos inferiores, salvo o primeiro decil. Para este, são observadas taxas de participação bastante baixas, em torno de $30 \%$ em certas regiões.

Este dado aponta para uma inserção potencial elevada no mercado de trabalho na maioria das regiões e decis, havendo déficit de participação econômica apenas no primeiro decil, segundo a renda familiar. Isso indica, ademais, queo perfil desfavorável de renda não seencontra associado à reduzida participação da população no mercado de trabalho, mas é resultado da renda auferida na atividade econômica exercida ou da situação de desemprego.

Temos nesse sentido uma primeira sinalização de que, ao menos no Estado de São Paulo, a melhoria das condições de vida, condicionada ao padrão de renda auferido, tem no comportamento do mercado de trabalho um determinante altamente relevante. Afinal, se os dados comprovam uma inserção potencial favorável e um padrão de renda desfavorável, o favorecimento das condições de inserção tende a ser central para uma provável mudança do padrão de renda da população do Estado. É necessário, pois, analisar o perfil atual da inserção da população no mercado de trabalho. 


\begin{tabular}{l|c|c|c|c|c|c|c|c|c|c|c}
\hline${ }^{1}$ Decil & $2^{0}$ Decil & $3^{0}$ Decil & $4^{0}$ Decil & $5^{0}$ Decil & $6^{0}$ Decil & $7^{0}$ Decil & $8^{0}$ Decil & $9^{0}$ Decil & $1^{\circ}$ Decil & Total \\
\hline Total & 41,9 & 54,0 & 48,0 & 56,9 & 56,2 & 60,9 & 60,9 & 61,7 & 66,4 & 67,9 & 58,3 \\
RM de São Paulo & 48,6 & 57,7 & 53,1 & 61,5 & 60,1 & 65,0 & 64,7 & 64,3 & 68,5 & 70,0 & 62,2 \\
Baixada Santista & 42,3 & 50,9 & 50,9 & 58,3 & 55,8 & 57,9 & 54,6 & 54,1 & 63,6 & 57,7 & 55,2 \\
RA de Campinas & 29,4 & 50,3 & 43,4 & 46,5 & 49,3 & 58,9 & 57,7 & 60,4 & 67,0 & 65,3 & 54,6 \\
RA de Registro & 36,6 & 44,9 & 44,5 & 47,7 & 45,8 & 56,0 & 57,3 & 51,2 & 63,1 & 51,8 & 47,6 \\
RA de Sorocaba & 39,9 & 51,6 & 47,3 & 56,7 & 50,4 & 60,3 & 59,3 & 62,4 & 57,8 & 71,8 & 55,7 \\
RA de São José dos Campos & 36,5 & 54,6 & 51,5 & 57,0 & 55,4 & 56,6 & 63,1 & 63,2 & 57,7 & 62,0 & 55,6 \\
Aglomerado Central Norte & 35,5 & 48,1 & 40,7 & 55,2 & 53,9 & 53,8 & 53,6 & 56,3 & 60,9 & 62,5 & 53,4 \\
Aglomerado Noroeste & 32,5 & 47,9 & 36,2 & 50,7 & 54,3 & 56,9 & 57,8 & 58,5 & 70,1 & 72,8 & 52,8 \\
\hline
\end{tabular}

Fonte: Pesquisa de Condições de Vida - PCV/Seade. Microdados. Elaboração própria.

TABELA 4

Taxa de Desemprego segundo Regiões e Decis de Renda Familiar Estado de São Paulo, 2006

\begin{tabular}{|c|c|c|c|c|c|c|c|c|c|c|c|}
\hline & $I^{0}$ Decil & $2^{\circ}$ Decil & $3^{\circ}$ Decil & $4^{0}$ Decil & $5^{0}$ Decil & $6^{\circ}$ Decil & $7^{0}$ Decil & $8^{\circ}$ Decil & $9^{\circ}$ Decil & $10^{\circ}$ Decil $\mid$ & Total \\
\hline Total & 52,2 & 27,7 & 22,2 & 18,5 & 14,8 & 12,3 & 11,7 & 12,5 & 8,6 & 45,4 & 16,0 \\
\hline RM de São Paulo & 48,5 & 27,8 & 24,0 & 19,7 & 15,9 & 13,6 & 13,0 & 13,5 & 10,4 & 6,3 & 17,0 \\
\hline Baixada Santista & 48,8 & 27,4 & 21,3 & 16,4 & 19,4 & 13,9 & 12,0 & 14,0 & 12,9 & 5,5 & 17,0 \\
\hline RA de Campinas & 55,1 & 29,7 & 22,1 & 15,0 & 11,7 & 9,6 & 8,3 & 13,9 & 5,1 & 2,5 & 13,1 \\
\hline RA de Registro & 53,4 & 29,3 & 21,5 & 20,8 & 20,6 & 11,9 & 20,2 & 7,2 & 6,2 & 10,7 & 22,9 \\
\hline RA de Sorocaba & 62,4 & 31,4 & 16,6 & 23,6 & 16,5 & 15,7 & 9,6 & 11,4 & 10,3 & 2,7 & 17,8 \\
\hline RA de São José dos Campos & 52,3 & 33,0 & 30,3 & 19,5 & 13,9 & 13,4 & 18,4 & 15,8 & 13,3 & 6,6 & 20,2 \\
\hline Aglomerado Central Norte & 76,4 & 19,8 & 11,8 & 15,9 & 7,7 & 10,1 & 9,0 & 5,0 & 4,1 & 5,1 & 11,7 \\
\hline Aglomerado Noroeste & 55,9 & 25,5 & 20,4 & 16,6 & 15,4 & 7,9 & 10,2 & 10,6 & 4,8 & 1,9 & 14,8 \\
\hline
\end{tabular}

Fonte: Pesquisa de Condições de Vida - PCV/Seade. Microdados. Elaboração própria.

A situação de desemprego é a primeira dimensão que merece ser explorada, por dois motivos. O primeiro decorre do fato de que quase não há dados sobre desemprego para além da Região Metropolitana. A PCV, ao adotar a perspectiva metodologia da pesquisa de emprego e desemprego, propicia alguma sinalização nesse sentido. $O$ segundo diz respeito ao fato de que o desemprego impede a possibilidade de acesso a qualquer tipo de renda no mercado de trabalho.

Feitas estas observações gerais, merecem destaque os resultados da PVC quanto à situação de elevado desemprego no Estado como 
[10] O desemprego mensurado pela PCV incorpora duas situações básicas: desemprego aberto - indivíduos que se encontram numa situação involuntária de não-trabalho, por falta de oportunidade; procuraram trabalho de maneira efetiva nos trinta dias anteriores ao da entrevista e não trabalharam nos últimos sete dias; desemprego oculto - indivíduos que realizam trabalhos precários - com remuneração ocasional de auto-ocupação ou trabalho não-remunerado em ajuda a negócios de parentes - e procuraram substituir esse tipo de atividade nos trinta dias anteriores ao da entrevista ou não tiveram êxito em até doze meses antes; inclui também as pessoas que não possuem trabalho nem o procuraram nos trinta dias anteriores ao da entrevista por desestímulos do mercado de trabalho ou por circunstâncias fortuitas, mas apresentaram procura efetiva nos últimos doze meses (Seade, 2007).

[11] Desmentindo a tese amplamente propalada durante o processo de reorganização das economias capitalistas avançadas a partir da década de 1970, o trabalho assalariado tem ampliado sua participação nos mercados nacionais. Dados compilados pela Organização de Cooperação para o Desenvolvimento Econômico mostram que as economias com maior grau de desenvolvimento ampliaram a participação do assalariamento em seus mercados de trabalho, que atualmente supera $80 \%$ do total de ocupados. $\mathrm{O}$ aspecto delicado desse movimento foi a redução acentuada do emprego por tempo indeterminado e a conseqüente ampliação das formas de emprego de duração limitada e em tempo parcial.VerOECD.Employment Outlook. Paris: OECD, 2007. um todo (Tabela 4). Os resultados mostram um desemprego total 10 de 16\% para o conjunto do Estado, sendo que o Aglomerado Central Norte apresentava a menor taxa (11,7\%) e a Região de Registro a maior $(22,9 \%)$. A situação de desemprego na região com a posição mais favorável atingiu uma de cada dez pessoas economicamente ativas. Conseqüentemente, o problema de emprego é parte recorrente do mercado de trabalho paulista, não importando a região considerada. Isto é, não se trata de um problema circunscrito à Região Metropolitana.

Como esperado, em um mercado de trabalho predominado pelo baixo rendimento, o quadro social apresenta-se mais delicado para as famílias dos estratos inferiores. No primeiro decil, o desemprego tende a atingir uma de cada duas pessoas ativas e no segundo, aproximadamente, três de cada dez. É inegável que o desemprego se constitui em um problema relevante para explicar a precariedade de renda nas diversas regiões do Estado de São Paulo, não podendo ser associado a uma região específica.Sobretudo quando o relacionamos com o rendimento familiar, desvinculando-o da dimensão individual que normalmente caracteriza a taxa de desemprego na forma clássica de sua utilização.

Cabe ainda apontar que a configuração do desempregoéclaramente predominada pela situação de "desemprego aberto", que responde por $2 / 3$ do desemprego total nas diversas regiões, o que denota a generalização desse problema no território paulista.

Analisando agora a situação de ocupação, dois indicadores serão considerados: a taxa de formalização, istoé, a porcentagem deocupados com contribuição para a previdência social, e a taxa de assalariamento, indicador da importância do trabalho assalariado nos mercados regionais de trabalho. A maior densidade desses indicadores pode ser tomada como expressão de maior complexidade da estrutura produtiva ${ }^{11}$.

No conjunto do Estado de São Paulo, 2/3 dos ocupados contribuía para a previdência social, sendo que a situação mais favorável era encontrada no Aglomerado Central Norte $(71,8 \%)$ e a mais desvantajosa na Região de Registro (57,1\%).

O grau de formalização do mercado estadual de trabalho variava com a renda familiar, porém ele era relativamente baixo mesmo para os decis superiores da distribuição (Tabela 5). Os indicadores segundo região mostram que, mesmo nestes estratos, a formalização não superava $70 \%$ da população ocupada. Isto é, três de cada dez ocupados em famílias de renda mais alta não contribuíam para a previdência social no Estado mais desenvolvido do país. Ademais, esta situação ocorre na principal região metropolitana brasileira, indicando que a formalidade dos contratos de trabalho, assalariado ou não, se constitui em um problema estrutural do mercado de trabalho brasileiro, independentemente do grau de desenvolvimento regional alcançado. 
O quadro de formalização limitada encontrado entre as famílias de renda mais elevada torna compreensível a situação de maior debilidade do indicador entre as famílias de baixa renda, especialmente no primeiro decil. Compreensível porque as ocupações mais precárias e com vínculos bastante instáveis têm alta concentração entre a população mais pobre, uma vez que a própria característica da relação de trabalho destas ocupações tende a apresentar baixíssimo grau de contribuição para a previdência social. Portanto, se o reduzido grau de formalização observado nos primeiros decis tende a refletir a precariedade da relação de trabalho dominante na base da estrutura ocupacional, tem-se que nos decis superiores ele deve expressar um modelo de regulação pública das relações e do contrato de trabalho incapaz de ordenar o mercado de trabalho do Estado. Afinal, qual a razão de ocupados mais bem situados socialmente não realizar a contribuição para a previdência social que não seja derivada de uma decisão voluntária e que tenha baixo risco de ser punida pela política pública ${ }^{12}$ ?

Quando considerada a taxa de assalariamento, percebe-se que, em média, 2/3 dos ocupados de cada região encontram-se vinculados a uma relação de trabalho subordinada. Em comparação com os países desenvolvidos, onde esta taxa supera $75 \%$ dos mercados nacionais de trabalho, pode-se considerar que o assalariamento tem uma dimensão mais limitada no mercado de trabalho paulista, apesar de dominante. Quando analisada a taxa de assalariamento segundo renda familiar, percebe-se que o indicador apresenta uma baixa intensidade no primeiro decil, sendo, ao menos, de 50\% a partir do segundo decil.

Apesar de seu nível relativamente limitado, pode-se argumentarque o assalariamento é a relação de trabalho de referência no Estado de São Paulo, e, portanto, indica a inserção econômica das famílias, independentemente da renda por elas auferida (Tabela 6). Assim, problemas de dinâmica econômica que venham afetar negativamente o nível de assalariamento tendem a amplificar os problemas de desemprego, pois $2 / 3$ das ocupações paulistas advêm da relação de trabalho subordinada.

Nesse sentido, incrementos de renda familiar estão diretamente relacionados com a dinâmica do segmento assalariado do mercado de trabalho e, portanto, dependem do desempenho global da economia em todas as regiões do Estado.

\section{O ACESSO A BENS PÚBLICOS E À POLÍTICA SOCIAL SOB A ÓTICA DA RENDA FAMILIAR}

Explorados a características básicas de inserção econômica da população do Estado de São Paulo e suas implicações para a renda familiar,é fundamental agora avaliar o acesso a bens públicos e às políticas sociais. Tal acesso amplia o consumo, ou o bem-estar, para além do padrão potencial propiciado pela renda auferida no mercado de trabalho.
[12] No Brasil, inexiste punição para a não contribuição da previdência social. $O$ ocupado que não contribui somente não terá acesso ao beneficio de aposentadoria ou pensão. Tratase de uma situação anômala, dentro do marco regulatório das sociedades capitalistas modernas, em que a não contribuição é punida de modo equivalente àquela feita em relação ao não pagamento do imposto de renda. A situação dos Estados Unidos constitui um exemplo relevante, por ser um país onde a regulação pública do contrato de trabalho ou de prestação de serviço é considerada a mais reduzida entre aquelas adotadas nos países desenvolvidos. As únicas duas obrigações que devem ser cumpridas, nacionalmente, pelo contrato de trabalho ou de prestação de serviços são o recolhimento do imposto de renda e a contribuição obrigatória para a previdência social. 
TABELA 5

Taxa de Formalização segundo Regiões e Decis de Renda Familiar (1)

Estado de São Paulo, 2006

\begin{tabular}{|c|c|c|c|c|c|c|c|c|c|c|c|}
\hline & $1^{0}$ Decil & $2^{0}$ Decil & $3^{\circ}$ Decil & $4^{0}$ Decil & $5^{0}$ Decil & $6^{0}$ Decil & $7^{0}$ Decil & $8^{\circ}$ Decil & $9^{\circ}$ Decil & $10^{\circ}$ Decil & Total \\
\hline Total & 21,7 & 48,3 & 54,6 & 57,9 & 63,1 & 64,2 & 68,4 & 71,0 & 71,4 & 70,0 & 64,7 \\
\hline RM de São Paulo & 20,2 & 46,6 & 52,0 & 53,1 & 61,5 & 56,5 & 66,0 & 71,0 & 71,1 & 71,5 & 62,8 \\
\hline Baixada Santista & 26,4 & 42,4 & 47,0 & 57,7 & 61,5 & 63,6 & 61,3 & 75,0 & 70,5 & 72,9 & 64,2 \\
\hline RA de Campinas & 18,3 & 47,3 & 62,1 & 63,8 & 65,5 & 72,4 & 68,0 & 71,0 & 67,8 & 71,5 & 67,3 \\
\hline RA de Registro & 28,5 & 48,4 & 60,6 & 45,5 & 52,6 & 61,6 & 74,7 & 58,7 & 67,2 & 62,8 & 57,1 \\
\hline RA de Sorocaba & 31,4 & 52,5 & 62,4 & 57,9 & 60,7 & 73,0 & 71,5 & 72,8 & 79,8 & 64,8 & 66,2 \\
\hline RA de São José dos Campos & 13,8 & 52,4 & 52,9 & 64,9 & 67,6 & 63,1 & 67,7 & 66,2 & 70,9 & 66,0 & 63,2 \\
\hline Aglomerado Central Norte & 37,5 & 58,6 & 59,6 & 72,6 & 71,9 & 75,2 & 77,9 & 69,5 & 70,3 & 76,1 & 71,8 \\
\hline Aglomerado Noroeste & 29,1 & 49,5 & 52,3 & 58,6 & 60,5 & 74,5 & 72,8 & 73,3 & 79.2 & 61,0 & 64,6 \\
\hline
\end{tabular}

(1) Foram consideradas ocupações formais aquelas com contribuição para a previdência.

Fonte: Pesquisa de Condições de Vida - PCV/Seade. Microdados. Elaboração própria.

TABELA 6

Taxa de Assalariamento segundo Regiões e Decis de Renda Familiar (I)

Estado de São Paulo, 2006

\begin{tabular}{|c|c|c|c|c|c|c|c|c|c|c|c|}
\hline & $1^{0}$ Decil & $2^{0}$ Decil & $3^{0}$ Decil & $4^{0}$ Decil & $5^{0}$ Decil & $6^{0}$ Decil & $7^{\circ}$ Decil & $8^{\circ}$ Decil & $9^{\circ}$ Decil & $10^{\circ}$ Decil $\mid$ & Total \\
\hline RM de São Paulo & 31,4 & 57,3 & 57,4 & 64,0 & 64,1 & 63,2 & 69,6 & 71,4 & 72,7 & 63,6 & 64,1 \\
\hline Baixada Santista & 33,3 & 50,3 & 42,7 & 56,0 & 70,1 & 61,9 & 58,6 & 62,5 & 64,8 & 66,6 & 61,1 \\
\hline RA de Campinas & 41,5 & 52,2 & 63,5 & 69,3 & 60,9 & 73,9 & 68,2 & 69,6 & 73,0 & 59,5 & 65,1 \\
\hline RA de Registro & 48,2 & 56,5 & 66,0 & 50,6 & 60,0 & 65,7 & 72,9 & 61,7 & 74,4 & 55,1 & 60,2 \\
\hline RA de Sorocaba & 24,8 & 52,9 & 65,6 & 59,7 & 66,7 & 77,2 & 74,1 & 71,2 & 70,9 & 61,5 & 65,6 \\
\hline RA de São José dos Campos & 22,8 & 54,4 & 67,2 & 68,4 & 66,0 & 71,4 & 68,4 & 71,9 & 72,7 & 64,3 & 65,7 \\
\hline Aglomerado Central Norte & 43,0 & 63,1 & 63,7 & 68,6 & 71,6 & 69,6 & 73,7 & 60,3 & 66,7 & 56,5 & 64,4 \\
\hline Aglomerado Noroeste & 36,0 & 54,9 & 57,1 & 63,9 & 71,0 & 75,2 & 72,4 & 68,6 & 69,7 & 60,5 & 64,8 \\
\hline Total & 32,6 & 56,3 & 59,3 & 64,6 & 65,5 & 67,8 & 69,9 & 69,4 & 71,5 & 62,1 & 64,4 \\
\hline
\end{tabular}

(1) Assalariados, salvo o emprego doméstico, no total da população ocupada.

Fonte: Pesquisa de Condições de Vida - PCV/Seade. Microdados. Elaboração própria.

Como para a maioria da população não é possível auferir uma remuneração mediante o exercício do trabalho que viabilize um padrão de vida adequado, seja devido à baixa remuneração associada à precariedade das ocupações, seja por causa do elevado nível de desemprego, o acesso a bens públicos e à política social passa a ser um meio crucial para o padrão de consumo das famílias.

Entre as formas de acesso existentes para a população brasileira, o Programa Bolsa Família é o que apresenta maior visibilidade. A dimensão desse programa e o envolvimento das instituições públicas 
em sua execução permitiram que, em um curto espaço de tempo, ele alcançasse 12 milhões de famílias pobres para o conjunto do país.

Segundo a PVC, 999 mil famílias tinham acesso ao Programa Bolsa Família em 2006 (Tabela 7). Em termos médios, oito de cada dez famílias paulistas recebiam o benefício do programa. A maior incidência ocorreu na Região de Registro, onde $17,8 \%$ das famílias eram beneficiárias do programa.

Analisando a distribuição das famílias segundo a renda, verificouse que $50 \%$ pertenciam até $03^{\circ}$ decil, istoé, possuíam uma renda familiar média de $\mathrm{R} \$ 660,00$, aproximadamente dois salários mínimos. Considerando o tamanho médio das famílias, pode-se afirmar que as pertencentes até $03^{\circ}$ decil tinham uma renda percapita próxima à renda de acesso ao programa, 1/2 salário mínimo.

Entretanto, surpreendeu o fato de uma parcela considerável de famílias pertencentes a estratos mais elevados de renda, ter acesso a este benefício, mas não cabe aqui discutir especificamente esta questão.

O ponto a ser realçado neste ensaio diz respeito à contribuição do programa de transferência de renda para as famílias (Tabela 8). Focando a análise nas famílias pertencentes até o $3^{\circ}$ decil, nota-se uma contribuição mais expressiva do benefício para as pertencentes ao primeiro decil, da ordem de $20 \%$. Esta contribuição, segundo a PCV, apresentou valores mais elevados nas regiões metropolitanas de São Paulo e da Baixada Santista.

Apesar da maior incidência do benefício nos estratos inferiores, o resultado da PCV revela que, em todas as regiões, as famílias pobres com acesso ao benefício têm no mercado de trabalho a referência decisiva para a formação de sua renda e de seu poder de compra. Mesmo no primeiro decil, aproximadamente $75 \%$ da renda familiar precisa ser atingida no mercado de trabalho, mesmo que seja na previdência social, cujo acesso se encontra condicionado a uma inserção econômica anterior.

Este resultado evidencia, ademais, o limite de um programa de transferência de renda em um Estado como o de São Paulo, onde predomina a monetização do consumo e das relações de trabalho. Limite que foi observado, então, nas diversas regiões consideradas pela PCV.

Mostraremos agora os resultados da pesquisa em relação a outros programas de transferência de renda, ligados à saúde, à educação, à habitação e ao saneamento. Qual programa social seria determinante para a caracterização das condições de vida da população?

O primeiro indicador a ser analisado diz respeito à política de atendimento à saúde. De acordo com a PCV, $75 \%$ das famílias paulistas declarou ter um posto de saúde em seu bairro de domicílio, sendo que esse dado aparece de modo um pouco superior entre as famílias de mais baixa renda. 
TABELA 7

Porcentagem de Famílias com Acesso a Programas de Transferência de Renda

Estado de São Paulo, 2006

\begin{tabular}{|c|c|c|c|c|c|c|c|c|c|c|c|}
\hline & $1^{0}$ Decil & $2^{\circ}$ Decil & $3^{\circ}$ Decil & $4^{0}$ Decil & | $5^{0}$ Decil & $6^{0}$ Decil & $7^{0}$ Decil & | $8^{\circ}$ Decil & $9^{\circ}$ Decil & $\mid 10^{\circ}$ Decil $\mid$ & Total \\
\hline \multicolumn{12}{|c|}{ Número de Famílias com Acesso ao Programa } \\
\hline Total & $|176.262|$ & 194.281 & | 132.181 & 112.756 & 113.835 & 75.132 & 44.196 & 32.251 & 15.279 & 97.984 & 994.158 \\
\hline \multicolumn{12}{|c|}{ Média de Membros por Família } \\
\hline Total & 2,7 & 3,1 & 3,2 & 3,2 & 3,3 & 3,4 & 3,2 & 3,5 & 3,5 & 3,4 & 3,3 \\
\hline \multicolumn{12}{|c|}{ Porcentagem de Famílias com Acesso ao Programa } \\
\hline Total & 14,6 & 18,9 & 12,8 & 11,1 & 11,2 & 7,3 & 4,2 & 3,2 & 1,5 & 3,5 & 8,2 \\
\hline RM de São Paulo & 16,8 & 18,4 & 16,7 & 11,3 & 14,3 & 4,7 & 3,8 & 3,4 & 2,3 & 2,3 & 8,5 \\
\hline Baixada Santista & 14,0 & 17,7 & 8,7 & 9,9 & 10,9 & 4,4 & 3,0 & 1,4 & 0,3 & 3,0 & 6,6 \\
\hline RA de Campinas & 8,8 & 14,8 & 8,0 & 5,8 & 5,8 & 13,0 & 2,8 & 2,6 & 0,6 & 3,2 & 6,2 \\
\hline RA de Registro & 23,8 & 37,2 & 14,1 & 20,3 & 14,9 & 13,5 & 5,8 & 5,7 & 0,0 & 11,4 & 17,8 \\
\hline RA de Sorocaba & 18,0 & 31,2 & 10,8 & 15,3 & 10,9 & 7,8 & 5,6 & 4,1 & 0,0 & 5,5 & 10,3 \\
\hline RA de São José dos Campos & 17,5 & 19,9 & 5,3 & 11,9 & 4,3 & 7,7 & 3,3 & 3,4 & 0,0 & 7,1 & 8,1 \\
\hline Aglomerado Central Norte & 15,0 & 18,3 & 9,9 & 12,9 & 9,7 & 11,3 & 8,0 & 4,5 & 0,7 & 4,0 & 8,8 \\
\hline Aglomerado Noroeste & 8,2 & 19,6 & 12,6 & 13,4 & 5,7 & 6,6 & 5,0 & 1,6 & 1,7 & 6,0 & 7,8 \\
\hline
\end{tabular}

Fonte: Pesquisa de Condições de Vida - PCV/Seade. Microdados. Elaboração própria.

TABELA 8

Contribuição das Transferências de Renda no Renda Familiar Total (I)

Estado de São Paulo, 2006

\begin{tabular}{|c|c|c|c|c|c|c|c|c|c|c|}
\hline & $1^{0}$ Decil & $2^{\circ}$ Decil & $3^{0}$ Decil & $4^{0}$ Decil & $5^{0}$ Decil & $6^{0}$ Decil & $7^{0}$ Decil & $8^{\circ}$ Decil & $9^{\circ}$ Decil & Total \\
\hline RM de São Paulo & 29,1 & 11,9 & 9,8 & 7,9 & 5,7 & 4,3 & 4,5 & 3,0 & 2,2 & 8,0 \\
\hline Baixada Santista & 30,5 & 14,7 & 10,9 & 7,3 & 6,8 & 3,9 & 4,0 & 3,1 & 1,2 & 9,2 \\
\hline RA de Campinas & 26,9 & 13,5 & 15,3 & 5,8 & 6,4 & 4,7 & 4,0 & 4,0 & 2,7 & 8,3 \\
\hline RA de Registro & 22,9 & 13,8 & 6,9 & 7,5 & 4,4 & 5,4 & 3,1 & 2,3 & $\cdots$ & 9,6 \\
\hline RA de Sorocaba & 25,1 & 11,7 & 9,0 & 6,9 & 4,8 & 2,5 & 4,0 & 3,3 & $\cdots$ & 7,3 \\
\hline RA de São José dos Campos & 23,0 & 10,5 & 7,3 & 6,8 & 4,8 & 5,0 & 2,1 & 1,2 & $\ldots$ & 8,2 \\
\hline Aglomerado Central Norte & 29,6 & 12,4 & 7,2 & 5,8 & 5,2 & 4,9 & 4,2 & 2,9 & 2,0 & 6,6 \\
\hline Aglomerado Noroeste & 16,0 & 10,4 & 8,4 & 6,0 & 3,4 & 3,6 & 3,6 & 2,2 & 2,3 & 6,1 \\
\hline Total & 27,0 & 12,1 & 9,7 & 7,0 & 5,6 & 4,3 & 4,1 & 3,0 & 2,2 & 7,6 \\
\hline
\end{tabular}

(1) Somente para as famílias com declaração de acesso ao programa.

Fonte: Pesquisa de Condições de Vida - PCV/Seade. Microdados. Elaboração própria.

Apesar de uma cobertura razoavelmente elevada da política de saúde para o conjunto do Estado, diferenças significativas são encontradas quando se analisa o indicador segundo as regiões da PCV (Tabela 9). Nas regiões de Sorocaba e Registro constata-se que 1/3 das famílias do primeiro decil declarou não ter posto de saúde no 
bairro de residência. Os resultados apontam discrepâncias razoáveis de cobertura entre as regiões, fato que sugere certa desigualdade de acesso ao atendimento primário de saúde, apesar de esta situação não estar relacionada com o nível de renda familiar. Ao contrário, os dados da pesquisa evidenciam uma menor cobertura justamente nos decis superiores, indicando que a política de saúde no Estado não é um instrumento de ampliação da desigualdade social existente.

Se do ponto de vista de acesso a um posto de saúde observa-se uma situação de diferenciação considerável, evidencia-se, por outro lado, uma cobertura adequada do Programa Saúde da Família (Tabela 10). Em média, as famílias paulistas recebem sete visitas por ano, sendo que esse atendimento médio pouco varia quando considerado o rendimento familiar.Ademais, quando consideradas as regiões, nota-se que a de Registro apresenta um indicador médio mais baixo que, porém, deve ser considerado satisfatório.

Quanto à cobertura da rede pública e privada de ensino fundamental, os resultados revelam algo semelhante ao encontrado para a política de saúde. Apesar de elevada, a cobertura mostra-se limitada. De 10 a $23 \%$ das famílias de baixa renda não possuíam escola de ensino fundamental em seus bairros, quando consideradas as regiões (Tabela 11).

A PCV não permite desagregar o indicador no interior de cada uma das regiões, o que seria adequado para identificar as áreas de cobertura da política de ensino fundamental. Contudo, ela permite analisar a cobertura da política por regiões segundo a situação de vulnerabilidade do domicílio a partir da área de sua localização (Gráfico 3). Nesse sentido, os resultados apontam não haver maior discrepância entre as áreas, com exceção da Região de Registro. Assim, os dados sugerem que a limitação da cobertura parece derivar de uma restrição associada à localização das escolas, ou seja, a ausência de escolas independe da fragilidade da situação social mais geral das famílias residentes em determinadas áreas.

Se do ponto de vista de acesso aos equipamentos de saúde e de educação não foram encontradas maiores discrepâncias entre as regiões, considerada a distribuição das famílias segundo seu nível de renda, contata-se uma situação significativamente diferente quando se analisam as condições de habitação e saneamento. A desigualdade de acesso a estes bens é substantiva.

A pesquisa revelou que, em $2006,6,8 \%$ das famílias paulistas residiam em favela, sendo que esta proporção era mais elevada entre aquelas com baixo nível de renda. Comparando as distribuições entre as regiões, nota-se a existência de duas regiões com uma parcela expressivamente mais elevadas de famílias residentes em favelas: as 
TABELA 9

Porcentagem de Famílias e Posto de Saúde no Bairro de Domicílio (Estado de São Paulo, 2006)

\begin{tabular}{|c|c|c|c|c|c|c|c|c|c|c|c|}
\hline & $1^{0}$ Decil & $2^{0}$ Decil & $3^{\circ}$ Decil & $4^{0}$ Decil & $5^{0}$ Decil & $6^{\circ}$ Decil & $7^{0}$ Decil & $8^{\circ}$ Decil & $9^{0}$ Decil & $10^{\circ}$ Decil & Total \\
\hline RM de São Paulo & 82,6 & 83,4 & 79,9 & 83,0 & 80,2 & 77,2 & 84,3 & 84,3 & 76,7 & 76,4 & 80,3 \\
\hline Baixada Santista & 83,2 & 71,1 & 83,9 & 78,2 & 81,4 & 83,8 & 68,5 & 81,6 & 87,1 & 78,9 & 79,8 \\
\hline RA de Campinas & 72,2 & 65,2 & 64,1 & 71,6 & 73,5 & 75,5 & 65,9 & 68,3 & 66,9 & 71,4 & 69,8 \\
\hline RA de Registro & 63,3 & 52,9 & 44,3 & 55,8 & 55,1 & 63,3 & 61,1 & 57,6 & 49,7 & 61,5 & 57,0 \\
\hline RA de Sorocaba & 63,9 & 79,8 & 65,2 & 68,7 & 68,7 & 55,7 & 54,6 & 55,6 & 62,9 & 58,4 & 62,6 \\
\hline RA de São José dos Campos & 83,7 & 48,2 & 41,0 & 35,6 & 57,1 & 36,5 & 34,1 & 49,6 & 43,2 & 62,4 & 49,3 \\
\hline Aglomerado Central Norte & 63,4 & 61,4 & 70,5 & 66,8 & 67,8 & 70,5 & 73,4 & 66,5 & 72,9 & 80,6 & 70,6 \\
\hline Aglomerado Noroeste & 77,6 & 73,0 & 80,2 & 81,8 & 73,9 & 73,9 & 77,7 & 79,2 & 73,0 & 73,9 & 76,1 \\
\hline Total & 84,1 & 76,3 & 72,8 & 75,7 & 75,9 & 71,68 & 74,1 & 76,2 & 71,7 & 73,3 & 74,5 \\
\hline
\end{tabular}

Fonte: Pesquisa de Condições de Vida - PCV/Seade. Microdados. Elaboração própria.

TABELA 10

Média anual de visitas de equipe do Programa Saúde da Familia - Evolução da População Residente

\begin{tabular}{|c|c|c|c|c|c|c|c|c|c|c|c|}
\hline & $1^{0}$ Decil & $2^{\circ}$ Decil & $3^{\circ}$ Decil & $4^{0}$ Decil & $5^{0}$ Decil & $6^{\circ}$ Decil & $7^{0}$ Decil & $8^{\circ}$ Decil & $9^{\circ}$ Decil & $10^{\circ}$ Decil & Total \\
\hline RM de São Paulo & 7,3 & 7,6 & 6,4 & 6,1 & 6,5 & 7,0 & 5,3 & 6,0 & 6,5 & 6,2 & 6,5 \\
\hline Baixada Santista & 7,1 & 11,5 & 6,7 & 6,2 & 6,1 & 7,1 & 7,9 & 4,6 & 5,0 & 6,4 & 7,0 \\
\hline RA de Campinas & 6,5 & 7,9 & 6,9 & 6,4 & 6,1 & 8,1 & 7,3 & 5,3 & 7,1 & 7,3 & 7,0 \\
\hline RA de Registro & 5,6 & 5,3 & 6,2 & 5,0 & 7,5 & 5,7 & 3,9 & 3,9 & 4,1 & 5,9 & 5,5 \\
\hline RA de Sorocaba & 6,3 & 7,1 & 7,2 & 7,9 & 7,8 & 6,5 & 5,1 & 5,2 & 7,9 & 5,7 & 6,7 \\
\hline RA de São José dos Campos & 7,2 & 6,9 & 6,1 & 5,0 & 5,7 & 5,0 & 6,4 & 7,5 & 4,8 & 5,7 & 6,1 \\
\hline Aglomerado Central Norte & 6,7 & 7,2 & 6,1 & 5,7 & 4,5 & 6,0 & 5,3 & 4,0 & 3,8 & 5,6 & 5,5 \\
\hline Aglomerado Noroeste & 8,0 & 7,7 & 10,1 & 7,9 & 8,1 & 8,5 & 7,1 & 8,8 & 8,9 & 9,4 & 8,6 \\
\hline Total & 7,1 & 7,7 & 7,1 & 6,4 & 6,5 & 7,2 & 6,1 & 6,0 & 6,5 & 7,0 & 6,8 \\
\hline
\end{tabular}

Fonte: Pesquisa de Condições de Vida - PCV/Seade. Microdados. Elaboração própria.

TABELA II

Porcentagem de Famílias e Escola de Ensino Fundamental no Bairro de Domicílio (Estado de São Paulo, 2006)

\begin{tabular}{|c|c|c|c|c|c|c|c|c|c|c|c|}
\hline & $1^{0}$ Decil & $2^{\circ}$ Decil & $3^{\circ}$ Decil & $4^{0}$ Decil & $5^{0}$ Decil & $6^{\circ}$ Decil & $7^{0}$ Decil & $8^{\circ}$ Decil & $9^{0}$ Decil & $10^{\circ}$ Decil & Total \\
\hline RM de São Paulo & 89,4 & 90,1 & 90,4 & 91,1 & 91,4 & 90,8 & 94,3 & 93,4 & 95,0 & 92,5 & 91,9 \\
\hline Baixada Santista & 89,1 & 85,7 & 92,0 & 92,3 & 91,8 & 91,3 & 94,8 & 93,5 & 96,7 & 92,3 & 92,1 \\
\hline RA de Campinas & 79,0 & 78,7 & 85,8 & 83,4 & 82,2 & 85,9 & 86,7 & 85,8 & 87,4 & 82,8 & 83,6 \\
\hline RA de Registro & 78,8 & 72,0 & 54,7 & 68,8 & 72,2 & 72,0 & 77,2 & 72,3 & 58,0 & 80,6 & 72,2 \\
\hline RA de Sorocaba & 84,6 & 88,2 & 84,0 & 83,7 & 85,4 & 75,8 & 79,4 & 77,4 & 88,9 & 86,3 & 83,6 \\
\hline RA de São José dos Campos & 83,2 & 77,3 & 83,4 & 87,7 & 86,6 & 80,3 & 85,4 & 81,4 & 81,6 & 84,2 & 83,3 \\
\hline Aglomerado Central Norte & 83,2 & 80,9 & 85,5 & 84,1 & 87,1 & 86,6 & 90,4 & 86,1 & 86,6 & 89,7 & 86,4 \\
\hline Aglomerado Noroeste & 80,8 & 81,4 & 80,3 & 83,5 & 79,4 & 83,4 & 72,0 & 82,6 & 83,0 & 80,3 & 80,4 \\
\hline Total & 85,7 & 85,8 & 87,0 & 87,7 & 87,6 & 87,3 & 89,1 & 88,7 & 91,0 & 88,3 & 87,9 \\
\hline
\end{tabular}

Fonte: Pesquisa de Condições de Vida - PCV/Seade. Microdados. Elaboração própria. 


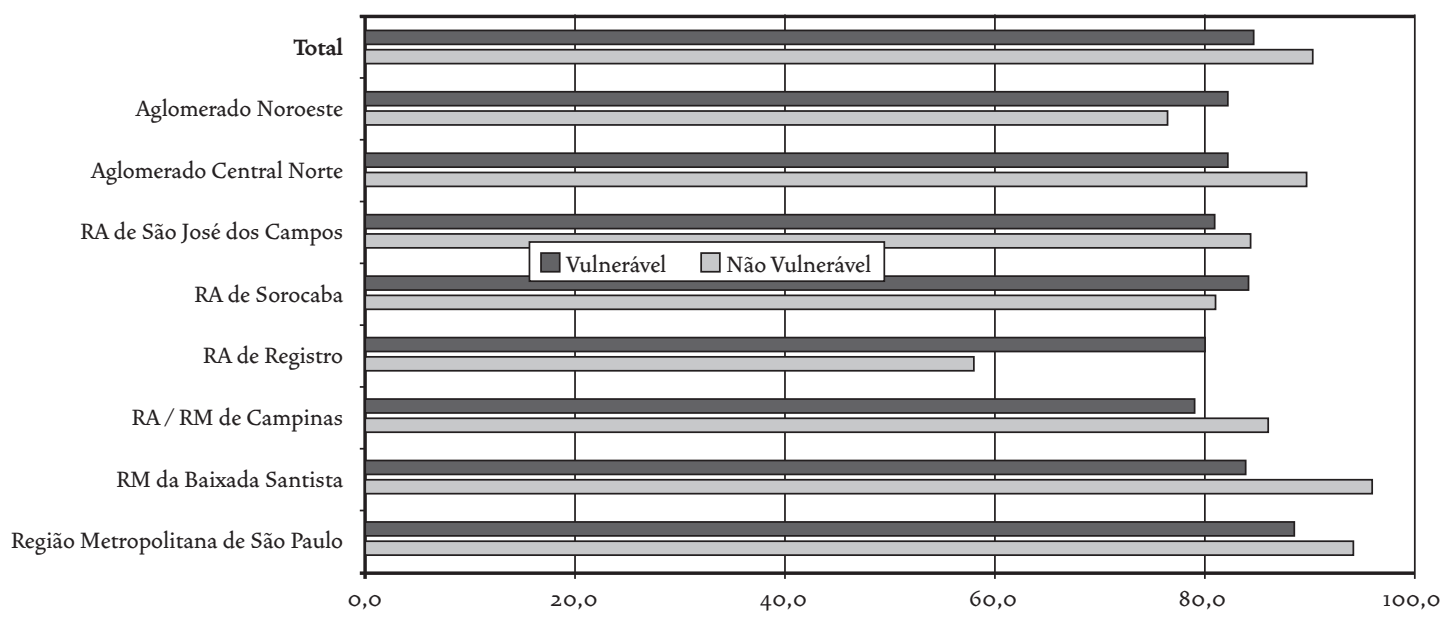

Fonte: Pesquisa de Condições de Vida - PCD/Seade. Microdados. Elaboração própria.

regiões metropolitanas de São Paulo e da Baixa Santista (Tabela 12). Uma de cada dez famílias dessas regiões encontrava-se nesta situação, sendo que, ao menos, uma de cada cinco famílias de baixa renda, considerados os dois primeiros decis.

A densidade da habitação em favelas é maior nas regiões de maior porte, visto que o custo da terra e dos aluguéis serem mais elevados e, em conseqüência, alimentarem uma ocupação desordenada de novas áreas urbanas por meio da criação de favelas. As regiões com menor densidade populacional, como as do Aglomerado Noroeste e de Registro, são as que apresentam menor incidência de famílias com residência em favela.

O aspecto complementar que merece ser destacado é a falta de associação entre residência em favela e localização habitacional em zona de enchente. A Região da Baixada Santista é a única com indicador elevado nesse sentido.

De acordo com a PCV, 4,5\% das famílias paulistas residem em áreas sujeitas a enchentes, sendo que as regiões da Baixa Santista e de Registro são as que apresentam indicadores mais elevados, especialmente entre a população de baixa renda (Tabela 13). Na primeira das regiões, três de cada dez famílias de baixa renda residem em áreas sujeitas a enchentes.

Quanto à Região de Registro, a maior exposição de domicílios em relação a riscos de enchentes está associada a particularidades de seu território, que encontra baixa densidade de ocupação e elevada presença de população com atividade agrícola em área montanhosa. É 
TABELA 12

Porcentagem de Famílias Residentes em Favelas

Estado de São Paulo, 2006

\begin{tabular}{|c|c|c|c|c|c|c|c|c|c|c|c|}
\hline & $1^{0}$ Decil & $2^{\circ}$ Decil & $3^{\circ}$ Decil & $4^{0}$ Decil & $5^{0}$ Decil & $6^{\circ}$ Decil & $7^{\circ}$ Decil & $8^{\circ}$ Decil & $9^{\circ}$ Decil & $10^{\circ}$ Decil & Total \\
\hline RM de São Paulo & 21,1 & 22,0 & 16,6 & 14,3 & 13,3 & 9,6 & 7,1 & 6,9 & 2,8 & 3,6 & 10,8 \\
\hline Baixada Santista & 25,3 & 28,9 & 18,0 & 17,4 & 11,8 & 9,8 & 6,2 & 5,3 & 3,4 & 3,6 & 11,4 \\
\hline RA de Campinas & 8,4 & 8,0 & 2,4 & 6,0 & 3,5 & 1,5 & 4,3 & 4,1 & 3,8 & 3,6 & 4,4 \\
\hline RA de Registro & 0,8 & 2,0 & 1,1 & 0,2 & 0,9 & 0,4 & 0,0 & 2,6 & 0,6 & 1,0 & 1,0 \\
\hline RA de Sorocaba & 5,4 & 6,0 & 4,6 & 0,0 & 1,2 & 1,6 & 1,4 & 0,0 & 0,0 & 0,7 & 2,0 \\
\hline RA de São José dos Campos & 3,9 & 1,8 & 1,0 & 1,7 & 1,0 & 1,2 & 0,0 & 0,6 & 0,0 & 0,1 & 1,1 \\
\hline Aglomerado Central Norte & 6,1 & 1,6 & 0,9 & 1,2 & 0,7 & 0,0 & 0,0 & 0,0 & 0,0 & 2,0 & 1,2 \\
\hline Aglomerado Noroeste & 0,7 & 1,1 & 0,0 & 0,5 & 1,0 & 0,0 & 0,0 & 0,0 & 0,8 & 0,3 & 0,4 \\
\hline Total & 13,9 & 14,5 & 9,1 & 8,9 & 7,7 & 5,3 & 4,5 & 4,2 & 2,3 & 2,7 & 6,8 \\
\hline
\end{tabular}

Fonte: Pesquisa de Condições de Vida - PCD/Seade. Microdados. Elaboraçãrópria.

TABELA 13

Porcentagem de Famílias com declaração de Residência em domicílios situados em áreas de enchentes Estado de São Paulo, 2006

\begin{tabular}{|c|c|c|c|c|c|c|c|c|c|c|c|}
\hline & $I^{0}$ Decil & $2^{\circ}$ Decil & $3^{\circ}$ Decil & $4^{0}$ Decil & $5^{0}$ Decil & $6^{0}$ Decil & $7^{0}$ Decil & $8^{\circ}$ Decil & $9^{\circ}$ Decil & $10^{\circ}$ Decil & Total \\
\hline RM de São Paulo & 6,3 & 6,9 & 5,1 & 4,6 & 6,5 & 5,1 & 4,8 & 5,2 & 94,5 & 5,8 & 5,5 \\
\hline Baixada Santista & 29,5 & 30,6 & 17,2 & 20,4 & 16,9 & 23,1 & 16,5 & 17,2 & 7,3 & 9,6 & 17,3 \\
\hline RA de Campinas & 2,0 & 3,7 & 2,1 & 2,9 & 1,1 & 1,5 & 1,3 & 0,8 & 0,3 & 0,9 & 1,5 \\
\hline RA de Registro & 14,5 & 11,3 & 12,4 & 17,3 & 8,5 & 15,1 & 10,3 & 3,8 & 16,9 & 9,0 & 12,0 \\
\hline RA de Sorocaba & 2,1 & 1,7 & 0,7 & 0,9 & 2,1 & 5,0 & 0,0 & 0,4 & 0,0 & 1,0 & 1,4 \\
\hline RA de São José dos Campos & 4,0 & 5,4 & 1,9 & 1,9 & 5,0 & 3,4 & 2,5 & 1,4 & 3,8 & 1,3 & 2,8 \\
\hline Aglomerado Central Norte & 1,7 & 5,7 & 4,9 & 0,4 & 3,1 & 0,0 & 0,4 & 1,2 & 0,8 & 1,8 & 1,9 \\
\hline Aglomerado Noroeste & 1,2 & 1,0 & 0,4 & 2,1 & 1,3 & 2,1 & 0,4 & 0,0 & 0,0 & 1,6 & 1,1 \\
\hline Total & 5,6 & 6,6 & 4,4 & 4,3 & 5,1 & 4,3 & 3,7 & 3,9 & 3,1 & 4,0 & 4,5 \\
\hline
\end{tabular}

Fonte: Pesquisa de Condições de Vida - PCD/Seade. Microdados. Elaboraçãrópria.

interessante, inclusive, observar que, como também ocorre na Baixada Santista, parte dos domicílios nesta situação pertence a famílias situadas nos decis superiores.

Comparando os indicadores de habitação em favelas eem área com risco de enchente, percebe-se a não convergência entre eles, indicando que o combate aos problemas não decorrem de um único instrumento de política pública.

O último indicador a ser explorado neste ensaio é o acesso à rede geral de esgotamento sanitário. A pesquisa indicou que $92 \%$ das fa- 
mílias residem em domicílios conectados à rede geral. Apesar da significância desse indicador, observam-se situações menos favoráveis nas regiões de São Paulo, Baixada Santista e Registro, sobretudo entre as famílias de baixa renda. Na Região de Registro, somente 60\% das famílias de baixa renda, considerados os dois primeiro decis, residiam em domicílios conectados à rede geral.

Os resultados relativos à habitação adequada e de saneamento básico mostram a precariedade de acesso a essas políticas públicas, evidenciando, ademais, sua centralidade para uma estratégia de desenvolvimento social do Estado (Tabela 14). Afinal, é inegável que os benefícios de programas de atendimento à saúde e de educação tendem a ser menores se mantidas as atuais condições de habitação da população de baixa renda.

TABELA 14

Porcentagem de Famílias em Domicílios com Rede Geral de Esgotamento Sanitário Estado de São Paulo, 2006

\begin{tabular}{|c|c|c|c|c|c|c|c|c|c|c|c|}
\hline & $1^{0}$ Decil & $2^{\circ}$ Decil & $3^{0}$ Decil & $4^{0}$ Decil & $5^{0}$ Decil & $6^{0}$ Decil & $7^{0}$ Decil & $8^{\circ}$ Decil & $9^{\circ}$ Decil & $10^{\circ}$ Decil & Total \\
\hline RM de São Paulo & 70,9 & 73,9 & 76,0 & 76,4 & 78,3 & 84,5 & 84,6 & 83,6 & 91,8 & 94,1 & 83,0 \\
\hline Baixada Santista & 59,2 & 54,2 & 73,0 & 70,8 & 69,0 & 80,4 & 76,9 & 81,9 & 80,0 & 91,0 & 76,4 \\
\hline RA de Campinas & 82,0 & 83,4 & 87,8 & 85,3 & 88,1 & 92,9 & 90,3 & 89,7 & 91,0 & 92,9 & 89,1 \\
\hline RA de Registro & 73,4 & 72,6 & 79,0 & 79,2 & 80,7 & 88,8 & 92,6 & 90,1 & 91,1 & 88,0 & 81,2 \\
\hline RA de Sorocaba & 92,5 & 94,4 & 97,8 & 92,8 & 96,1 & 99,1 & 97,4 & 99,8 & 99,3 & 98,7 & 97,0 \\
\hline RA de São José dos Campos & 90,7 & 87,1 & 90,1 & 92,8 & 92,3 & 91,9 & 93,3 & 97,4 & 97,5 & 96,4 & 93,5 \\
\hline Aglomerado Central Norte & 95,6 & 98,4 & 98,7 & 99,0 & 99,7 & 99,4 & 100,0 & 100,0 & 100,0 & 99,3 & 99,1 \\
\hline Aglomerado Noroeste & 100,0 & 98,9 & 98,4 & 99,4 & 94,2 & 100,0 & 99,5 & 100,0 & 100,0 & 96,8 & 98,1 \\
\hline Total & 82,9 & 84,0 & 88,9 & 87,9 & 88,9 & 94,2 & 93,4 & 97,8 & 97,8 & 99,3 & 92,1 \\
\hline
\end{tabular}

Fonte: Pesquisa de Condições de Vida - PCV/Seade. Microdados. Elaboração própria.

\section{OBSERVAÇÕES FINAIS}

A disponibilidade de dados recentes para o Estado de São Paulo estimulou em grande medida a realização desta iniciativa.É óbvio que as inquietações sobre as transformações socioeconômicas recentes na sociedade paulista também alimentaram a realização deste estudo.

Duas vantagens relativas às condições econômicas atuais devem ser ressaltadas para a qualidade da análise apreendida. A primeira diz respeito à baixa inflação que favorece a informação sobre renda, possibilitando que os resultados da PVC estejam nada ou pouco imunes a mudanças bruscas de preços relativos que possam comprometer a declaração de renda pelas famílias. A segunda refere-se à tendência de recuperação econômica no período de 2004 a 2008 , que permitiu a 
recomposição do nível de emprego no mercado de trabalho brasileiro, em especial o paulista, e que deve ter favorecido a coleta de informação sobre a situação ocupacional da população. Por fim, a PCV constitui-se em uma fonte de informação de grande interesse para a construção de conhecimento da configuração socioeconômica paulista no contexto atual. Este ensaio explorou parcialmente seu potencial estatístico. A análise mostrou condições razoavel mente homogêneas em termos de dinâmica populacional, inserção econômica e acesso a bens eà política pública no território paulista.

A distribuição do produto coincide com aquela da população nas diversas regiões consideradas pela PCV. Ademais, os resultados mostraram convergência das regiões quanto à inserção econômica da população, evidenciando um quadro bastante homogêneo em termos de desemprego e precariedade da situação ocupacional, medida pelo indicador de formalidade.

Ao focar a inserção econômica da população percebe-se a dominância dos setores econômicos pertencentes à atividade não-agrícola, apesar de certas regiões terem certa expressão em termos de ocupação e produto do setor agrícola. Em uma visão mais geral, é patente a ampla dominância das atividades não-agrícolas no território paulista e a dependência que a população dela possui para viabilizar sua inserção produtiva.

A análise desta inserção mostra um perfil de acentuada precariedade e de desemprego em todas as regiões do Estado, juntamente com uma configuração de renda bastante desfavorável. Assim, observa-se que o potencial produtivo da população é limitado e fonte de um padrão fundado na baixa renda.

Os programas de transferência de renda não parecem ser suficientes para modificar a reiteração da baixa renda para a maioria da população. Apesar de atenuarem a precariedade de renda das famílias pertencentes aos estratos inferiores, eles não são capazes de alterarem o quadro estruturalmente insatisfatório em que elas se encontram. Os dados da PCV apontam claramente que, considerado o grau de desenvolvimento da sociedade urbano-industrial paulista, a inserção produtiva se constitui na fonte predominante de renda das famílias, mesmo em uma região menos desenvolvida como a de Registro.

O quadro socioeconômico do Estado foi ampliado com a análise de acesso às políticas públicas de saúde eeducação, apresentando uma cobertura abrangente da população sem que haja diferenças significativas quando considerada a renda familiar. Contudo, nota-se ainda a existência de uma parcela de famílias que residem em bairros sem postos de saúde e escolas de ensino fundamental.

A razoável homogeneidade dos perfis socioeconômicos é rompida quando se analisa os indicadores de habitação e saneamento. Nas re- 
giões metropolitanas de São Paulo e da Baixada Santista, a situação de residência em favela é mais expressiva. Quando se considera o risco de enchentes para os domicílios, nota-se que as regiões da Baixada Santista e Registro apresentam maior incidência.

Esta situação de heterogeneidade observada para a condição habitacional é reiterada quando se avalia o acesso a saneamento básico. Além de uma cobertura limitada, nota-se também uma diferenciação importante entre as regiões.

Pode-se afirmar que os resultados da PCV indicam que modificações na situação socioeconômica do Estado de São Paulo, na próxima década, dependem estreitamente de um crescimento sustentado, em conjunção com a continuidade das políticas sociais, que favoreça a estruturação do mercado de trabalho com a redução da precariedade ocupacional e com a elevação dos níveis e melhoria da distribuição de renda. Esse processo é decisivo para viabilizar um padrão adequado de renda por meio da inserção produtiva, bem como para ampliar o financiamento estadual das políticas sociais. Tal necessidade não se restringe à Região Metropolitana de São Paulo, mas estende-se a todo o território estadual.

Recebido para publicação

em 25 de novembro de 2008.

NOVOS ESTUDOS

CEBRAP

84 , julho 2009

pp. 127-150 